\title{
O CONCEITO DE EXPERIÊNCIA NOS TRABALHOS DE WILLIAM JAMES E JOHN DEWEY E O TEATRO IMPROVISACIONAL DE VIOLA SPOLIN ${ }^{1}$
}

\section{The concept of experience in the works of William James and John Dewey, and the improvisational theater of Viola Spolin}

\author{
Karine Ramaldes \\ Robson Corrêa de Camargo \\ Universidade Federal de Goiás - UFG
}

Resumo: A partir da pesquisa bibliográfica relacionada com a prática pedagógica dos jogos teatrais, este artigo estabelece uma reflexão entre o sistema de Viola Spolin e o conceito de experiência, em algumas de suas abordagens, principalmente as reflexões a partir de William James e John Dewey. O estudo ocorre dentro do marco investigativo do mestrado e doutorado em Performances Culturais da Universidade Federal de Goiás.

Palavras-chave: Jogos Teatrais; Viola Spolin; Experiência; Improvisação.

Abstract: Based on the bibliographic research related to the pedagogical practice of theatrical games, this article establishes a reflection between the Viola Spolin system and the concept of experience, in some of its approaches, mainly the reflections of William James and John Dewey. The study takes place within the investigative framework of the master's and doctorate in Cultural Performances at the Federal University of Goiás.

Keywords: Theater Games; Viola Spolin; Experience; Improvisation. 
Tomemos como premissa, para uma compreensão mais profunda do sistema dos jogos teatrais os conceitos de experiência (Experience ou em sua versão alemã, Erlebniz), como foram desenvolvidos pelos filósofos William James (18421910) em seus Principles of Psychology (1890) e por John Dewey (1859-1952) em Experiência e Educação (1938). Atrás de uma aparente simplicidade o conceito apresenta uma discussão complexa que tem consequências profundas na análise da cultura e na relação ensino-aprendizagem.

A experiência não pode ser vista apenas como o locus da totalidade das sensações, de tudo que é vivenciado pelo ser humano, do não racionalizado, como foi utilizado o termo na primeira metade do século XIX, principalmente por Hegel (1770-1831) e Nietzsche (1844-1900). Nietzsche, corretamente, enfatizava a importância do corpo em oposição a alma, ao espírito ou ainda a forma substancial cartesiana, recuperava ele os sentidos do corpo como centro do conhecimento. Segundo Nietzsche há uma pluralidade de forças, afetos, pulsões, ou seja, uma luta de instintos tiranos do corpo que suplanta nossa razão e consciência, e esta é parte do corpo, não está acima dele ou além dele, subvertendo assim a noção do sujeito cartesiano. Não seria então a consciência que definiria a subjetividade, mas o corpo comporia uma nova matriz da subjetividade. Como afirmou Oswaldo Giacoia sobre o pensamento de Nietzsche: "o corpo pode servir de paradigma para a constituição de uma hipótese sobre a subjetividade, muito mais rica e plausível" (GIACOIA JUNIOR, 2001, p. 59). Afirmava Nietzsche que o corpo é a grande razão, individual e múltipla, matriz da constituição da subjetividade humana e de sua prática. Apesar desta importante contribuição ao entendimento da experiência, Nietzche pensava experiência em uma definição muito geral, como "uma superfície de inscrição dos acontecimentos, um lugar de dissociação do "eu", marcado de história" (Assim falava Zaratustra, 1979 [1883]).

Erlebnis, a experiência na perspectiva inicial do pensamento alemão, antes do desenvolvimento do diálogo intenso entre o compositor e diretor alemão de teatro Richard Wagner (1813-1883) e Nietzche, e, mesmo em alguns escritos de ambos, seria empregada no sentido estrito da totalidade de sensações, em oposição a racionalidade. Experienciar, para Nietzche, era apenas o sentir. Como 
afirma Viesenteiner, Nietzche nunca sistematizara o conceito de experiência (Erlebniz) em seus escritos, e a palavra ocorre em seus textos em significações variadas (VIESENTEINER, 2013, p. 147).

Vale a pena entender um pouco a formação e desenvolvimento do conceito de Erlebnis, a experiência no pensamento alemão. Esta surge na primeira metade do século XIX, se caracterizando inicialmente como uma oposição "intransigente à frieza da especulação metafísica e ao racionalismo da Aufklarung (esclarecimento)," o termo é, portanto, uma crítica aberta ao racionalismo ${ }^{2}$ (VIESENTEINER, 2013). A palavra erlebnis que também é traduzida por muitos ao português como vivência, surge no vocabulário alemão na primeira metade do século XIX e, como descreve Viesenteiner, ganha estatuto filosófico apenas em meados do século XIX, apresentando uma trajetória complexa e que supera este primeiro entendimento.

O conceito Erlebnis, em sua perspectiva particular inicial, se referia a determinadas experiências significativas da vivência humana em seu processo de conhecimento do mundo, numa relação claramente individual, como algo que se constrói e interfere de modo significativo na vida, algo que altera nosso modo de vida profundamente, como fruto de nossa existência social e do processo constante de conhecimento. Estava ligado ao imediato, ao estar em vida, e também a algo que superava o conteúdo racional da existência, nem apenas a sensação nem a representação, uma unidade de conhecimento do indivíduo entre o afeto e o conceito e a experiência de vida.

A experiência assim seria o início de um processo de conhecimento que se antepunha a consciência, entendida esta como um processo único de compreensão da realidade, um processo distinto. Em vez do penso, logo existo, do pensamento como eixo do entendimento do mundo, temos agora com a Erlebnis um existir pensando, existir em pensamento onde não há um pensamento reflexivo que possa ser construído sem ação e sem existência. Assim, o conhecimento a partir da prática se constrói num pensamento que se elabora no processo da práxis

${ }^{2}$ Muitas destas questões são desenvolvidas com mais detalhes e propriedade pelo texto de Viesenteiner (2013) O conceito de vivencia (Erlebnis) em Nietzche. 
humana. Isto tem consequências no entendimento particular dos jogos teatrais e mais ainda no processo de compreensão e análise das atividades rituais. Há que se compreender assim o sistema de jogos teatrais como o de construção de um conhecimento que se inicia pela prática e se finaliza na prática do teatro improvisacional e, sim, se completa na avaliação, na reflexão, no racional como parte do processo, mas não pertence somente a ela, induzindo-se a um novo processo reflexivo em ato, a uma nova ação em pensamento, ação pensante, pensamento em ação. Assim há que se evitar o compreender os jogos teatrais num processo dual sequente, como o de um jogar e de um pensar posterior e concludente.

Bom, a tentação de se aprofundar no pensamento de Nietzsche é grande, mas dele devemos nos afastar. O conceito de experiência (Experience ou Erlebniz) se ampliará superando as colocações Nietzscheanas que inauguram esta reflexão e pode ser considerado hoje um dos principais conceitos na análise da cultura e das ações humanas e de sua prática.

Este conceito é tão importante que Dewey, um dos principais filósofos que abordou a questão da experiência profundamente, ao preparar uma nova introdução ao seu livro Experience and Nature de 1925, ao revisá-lo para a edição de 1951, um ano antes de sua morte, lamentou o uso equivocado do termo experiência devido ao exasperante mal-entendido de muitos que, ao lerem sua obra, o compreendiam como apenas uma manifestação individualista e cerebral (mentalist). Em retrospecto, ele desejou ter usado o termo cultura em substituição, para enfatizar o aspecto social da experiência (ver ALEXANDER 1987, p. 70), sendo que talvez o melhor nome para sua obra, segundo seu entendimento, devesse ser Cultura e Natureza, ideia não levada a cabo. Experiência então, é bom que se ressalte, é um fenômeno social, humano e não individual, embora inclua certamente aspectos da individualidade.

Dewey vai definir experiência de forma distinta àquela de Nietzsche, superando a perspectiva nietzschiana que a colocava apenas no corpo e como uma superfície de inscrição de acontecimentos, marcado pela história. Dewey apresenta duas formas de experiência. Uma forma de experiência primitiva, pura, crua, 
parcial, e outra forma, uma experiência "completa", que chamou também de experiência estética. Esta experiência última, completa, é uma experiência totalizadora de sentido para o ser humano (sentimento, emoção, impressão, consciência, paixão, cognição que se desenvolve de forma completa e complexa, unitária e simultânea). É importante que se reconheça esta unidade entre ação, afeto, emoção e cognição, para que não se entenda de forma simplificada que uma percepção vem primeiro que qualquer outra e, no caso do jogo teatral, como se houvesse um jogar e depois um momento do conhecer, reflexivo.

É senso comum o entendimento da distinção de pensamento e da ação, como se as coisas existissem em forma dual e a parte, existindo de forma independente, penso logo existo, existo e depois penso, um após o outro. Os jogos teatrais, nosso foco de reflexão, constroem-se como um sistema relacional em movimento, unidades complementares de afeto, da ação e de conhecimento, onde estes três processos são coetâneos, ocorrem ao mesmo tempo, no mesmo tempo, sem uma necessária ordem prévia, desenvolvendo-se em distintos momentos e diferentes maneiras onde um completa, complementa o outro.

A elaboração desta forma de entendimento da experiência se distancia, e muito, do pensar como ato maior que o ato de existir e da consciência como algo que aconteceria longe do sentir e do agir, como fenômeno à parte ou consequente, posterior. Neste sentido há uma grande correspondência entre o conceito de experiência desenvolvido por James e Dewey, com suas respectivas variantes, com o conceito de Erlebniz apresentado na filosofia alemã em seus vários diapasões.

Gadamer (1900-2002) ressalta o importante contato do pensamento alemão com o pragmatismo americano, principalmente em Heidegger (GADAMER, 2007, p. 12.). Em Gadamer, Dewey e James a experiência constrói um saber prático, a prática do saber ou, para usar outro termo, da práxis.

Podemos agora, por um momento, voltar a William James no século XIX. James como grande parte da intelectualidade dos Estados Unidos da época tinha fluência em alemão e em francês, o que incluiu inclusive alguns anos de estudos na Alemanha, depois de uma curta estada no Brasil nos anos de 1865-1866, com 
23 anos. James fez parte da Expedição Thayer, onde elaborou até um pequeno dicionário tupi-inglês, de uso privado, enquanto criticava a preguiça dos povos aqui nativos. Como um dos fundadores da psicologia experimental, James é responsável pelo conhecido paradigma que as emoções tem causas físicas primeiras, e não o contrário, a chamada teoria James-Lange ${ }^{3}$ que afirmava em seu conhecido exemplo que, se vemos um urso, corremos e consequentemente sentimos medo. As batidas de coração, o nível de adrenalina seriam as nossas emoções ou o provocar delas. A discussão é complexa e mereceria um maior detalhamento, impossível aqui neste curto espaço, mas ajuda ao entendimento do ponto de vista da experiência como um processo de sentir pensado ou, pelo menos, que se questione aqui o senso comum da relação pensar/sentir/agir numa ordem sequencial e isoladas.

Dewey, de certa forma seu discípulo, muito influenciado pelo pensamento de James, se doutora com uma tese sobre Kant em 1884, na Johns Hopkins University, o que evidencia seu profundo conhecimento da filosofia alemã ao lado de sua paixão pelo pensamento grego antigo. Dewey, em texto de 1930, refletindo sobre sua formação, afirmava ter sido uma das primeiras pessoas nos EUA a se "aventurar no especulativo, dúbio e ortodoxo pensamento alemão" (WARDE, 2013, p. 171). Estipuladas as relações intensas entre o pensamento alemão e os trabalhos de James e Dewey podemos nos deter agora em algumas questões levantadas pelos dois pragmatistas para se entender de forma densa um pouco mais profundamente o sentido em que se construiu o termo experiência.

O psicólogo e filósofo William James acreditava que seriam muitos os "reinos da realidade" que podemos experienciar. Neles o encontro do ser humano com a realidade não era apenas o de um simples encontro entre o eu e o externo a ser

\footnotetext{
${ }^{3}$ A teoria de James-Lange é uma hipótese sobre a origem e a natureza das emoções e é uma das primeiras teorias da emoção na psicologia moderna. Foi desenvolvido de forma independente por dois estudiosos do século XIX, William James e Carl Lange. A premissa básica da teoria é que a excitação fisiológica instiga a experiência da emoção. Em vez de sentir uma emoção e subsequente resposta fisiológica (corporal), a teoria propõe que a mudança fisiológica é primária, e a emoção é experimentada quando o cérebro reage às informações recebidas pelo sistema nervoso do corpo. Ele propõe que cada emoção específica esteja ligada a um padrão único e diferente de excitação fisiológica e comportamento emocional em reação devido a um estímulo emocionante.
} 
atravessado por determinado fenômeno. Há, para James, o mundo dos objetos físicos e da experiência sensorial; mas também o mundo da ciência; existe ainda a filosofia e a matemática e suas verdades abstratas e relações ideais; existem as distorções das ilusões e preceitos que nos acompanham e determinam nossos caminhos; há a mitologia e a ficção que compõe a nossa cultura; há a religião; e não podemos ignorar as opiniões subjetivas; e como não reconhecer o mundo da loucura que pode nos desconectar da realidade em que outros podem acreditar prontamente. Certamente habitamos e experienciamos ao mesmo tempo e durante nossa vida mais do que um destes mundos em que estamos e que nos determinam (JAMES, 1890, p. 292-299). Não somos sujeitos passivos, mas sim vivemos em uma realidade múltipla, com a qual interferimos e somos influenciados por ela, da mesma maneira que, ao ver uma igreja muitos fazem automaticamente o sinal da cruz.

Até cerca de 1870 a experiência não tinha ainda um status conceitual, Erlebniz era assim compreendida apenas como o estar presente na vida quando algo acontece, era a constatação de um estado. O surgimento deste conceito em sua forma ainda difusa tem relação com a busca por uma linguagem, um termo ou compreensão que se referisse aos sentimentos do homem ou da mulher e apresentasse a importância do conhecimento pelo e no viver em oposição ao simples pensar, a procura de um entendimento da vida que se fundasse nas "vivências" e não apenas no pensamento, naquilo que era vivido ou experienciado, em oposição a consciência. Vários pensadores procuravam elaborar outra forma de conhecimento que não fosse apenas o de pensar e sim o de existir, que se desenvolvia de forma avassaladora no reino do conhecimento humano impulsionado pelas chamadas ciências humanas.

Será o filósofo alemão Wilhelm Dilthey (1833-1911) o primeiro que irá aproximar a consciência e a vivência, ou a reconhecer os elementos de consciência do fenômeno da "pura" experiência: Afirmava Dilthey (apud BAND, 1922, p. 63) que: objetos e ideias, assim como sentimentos, são primeiramente vivências em minha consciência, onde experiência (Erlebnis) representaria o rigoroso instante em que "sentimos" algo, mas não um sentir sem pensar, ao contrário, um sentir 
pensado. Para dizer de outro modo, a relação teórica em Dilthey deriva de uma relação experimental que é primeiramente tanto prática quanto teórica. O mundo da experiência vivida não é apenas uma representação teórica, são valores incorporados, existimos em um mundo onde não há um simples encontro entre o eu e o externo, existem vários mundos onde experienciamos e construímos nossas sensações, a linguagem preexiste, a cultura preexiste, as distorções das ilusões, as mitologias e a ficção, as opiniões subjetivas preexistem.

Assim temos que o conteúdo da existência não é apenas sensação e/ou representação, e também não existe apenas um eu e um acontecimento exterior a mim. A experiência está correlacionada às diversas maneiras como experimentamos as coisas, e os significados que as coisas adquirem a partir de nossa experiência, ou seja, a experiência reflexiva é primordial na formação do conhecimento humano, uma relação dinâmica do agir e do pensar, um pensar agindo ou um agir pensando.

Hans-Georg Gadamer (1900-2002), outro filósofo alemão que se dedicou ao entendimento da experiência mais recentemente, a partir de 1960, em seu Verdade e Método, desenvolve o conceito de experiência em duas vertentes, incorporando a experiência com a reflexão, estabelecendo o que ele chama de Erlebnis, que seria experiência de vida e Erfahrung, que designaria a experiência científica. Neste contexto desenvolve um processo de formação do conhecimento que se apresenta como "o modo de perceber que vem do conhecimento e do sentimento...". Neste sentido, formação significa mais do que cultura, é um aperfeiçoamento de faculdades e talentos." (GADAMER, 2012 [1960], p. 45, 46). Para Gadamer "Na formação... é possível apropriar-se totalmente daquilo em que e através do que alguém é instruído. Nesse sentido, tudo que ele assimila, integra-se nele... $\mathrm{Na}$ formação adquirida nada desaparece tudo é preservado." (GADAMER, 2012 [1960], p. 47). Se Gadamer compreende que, na "formação adquirida nada desaparece tudo é preservado", percebe-se aqui uma estreita conexão com o 
conhecimento adquirido pelo acúmulo ${ }^{4}$ de experiências exposto anteriormente por James e principalmente por Dewey. O "acúmulo de experiências", nos leva a preservar ou desenvolver todas as experiências já vivenciadas, e é justamente a lembrança dessas experiências que nos auxilia na experiência presente e na formação do indivíduo como um todo.

A formação do indivíduo se constitui assim a partir da articulação das diferentes experiências que são vivenciadas, da cultura, na cultura, dos mundos, nos mundos, das memórias e pela capacidade reflexiva. Cada uma dessas experiências se integra no indivíduo que a vivenciou, ou seja, é a apropriação da experiência que gera a formação do indivíduo, portanto o conhecimento.

É possível perceber a experiência e seus acúmulos na formação do indivíduo na abordagem improvisacional dos jogos de Viola Spolin (1906-1994). Neste processo, os jogos improvisacionais se articulam para além do simples conhecimento da arte teatral e de algumas de suas técnicas. Vejamos, para Spolin improvisação é:

Jogar um jogo; predispor-se a solucionar um problema sem qualquer preconceito quanto à maneira de solucioná-lo; permitir que tudo no ambiente (animado ou inanimado) trabalhe para você na solução do problema; não é a cena, é o caminho para a cena; uma função predominante do intuitivo; entrar no jogo traz para as pessoas de qualquer tipo a oportunidade de aprender teatro; é "tocar de ouvido"; é processo, em oposição a resultado; nada de invenção ou "originalidade" ou "idealização"; uma forma, quando entendida, possível para qualquer grupo de qualquer idade; colocar um objeto em movimento entre os jogadores como um jogo; solução de problemas em conjunto; a habilidade para permitir que o problema de atuação emerja da cena; um momento nas vidas das pessoas sem que seja necessário um enredo ou estória para a comunicação; uma forma de arte; transformação... processo vivo. (SPOLIN, 2005 [1963], p. 341)

$\mathrm{Na}$ improvisação dos jogos teatrais, "processo vivo", então teremos uma articulação para a solução de problemas em ato, no processo de experiência,

4 O acúmulo de experiência é o que Dewey virá chamar de "princípio de continuidade" (DEWEY, 1971 [1938], p. 26), no qual a experiência do presente está sempre conectada a experiências do passado, numa constante construção do conhecimento. 
pensamento em ato, pois não haverá possibilidade de arranjo prévio. São utilizados todos os elementos que cercam os jogadores no momento do jogo (aqui/agora), elementos imaginários, sensitivos e corporais que surgem da relação entre os jogadores e da relação dos jogadores com o ambiente. Não sabemos o que irá acontecer, pois as alternativas são incontáveis, dependem de onde o grupo as está levando. No momento do jogo as experiências passadas, combinadas com as experiências presentes, transformam-se em uma nova experiência, ou seja, ocorre o processo de recriação, consequentemente levando os jogadores ao aprendizado dentro de uma perspectiva de ação no aqui e agora, e cabe aos jogadores se entregarem à experiência de jogar e aprender jogando, vivenciando ou melhor experienciando. É uma forma de aprendizado do jogo da vida, muito além do viver uma determinada regra de interpretação. Arte e vida se confundem.

Os jogos improvisacionais, ao jogar o caminho para a cena, impulsionam o intuitivo, o viver em ato, ao estar em grupo no momento presente, o focar na solução do problema e não no indivíduo. Estes elementos são partes constitutivas da vida, não apenas do teatro. Ao impulsionar o processo, em oposição ao resultado; nada de invenção ou predeterminação ou "originalidade" ou "idealização", aprende-se a viver na vida, e não na elaboração dela. Assim os jogos teatrais iniciam um processo de pensamento em ato fundamental para a experiência humana.

É evidente a ligação dos jogos teatrais com as técnicas teatrais. Ingrid Koudela (1991, p. 130) ressalta a influência do ator, diretor, pedagogo e escritor russo Constantin Stanislavski (1863-1938) no trabalho de estruturação dos jogos de Spolin. A própria definição de "improvisação" de Spolin está próxima à definição de Stanislavski. O ator russo, aprofundando os aspectos pedagógicos do fazer teatral e, em seu tempo criticando as formas tradicionais de ensino de teatro, nos dizia:

Quando o ensino se volta para um objetivo prático e até mesmo interessante, é mais fácil convencer e influenciar os estudantes. (...) Ao treinar os atores nosso ponto de partida é fazer com que aprendam através da atuação [improvisações]. (...) É impossível ficar anos ensinando numa sala de aula, e só no fim pedir a um estudante que represente. Nesse ínterim, ele terá perdido todas as suas faculdades criadoras. (...) A criatividade tem de ser um 
processo contínuo; nossa única preocupação deve ser a escolha do material em que fundamentá-la. Em nosso tipo de atuação, costumamos usar amplamente as improvisações. (...) Tal tipo de criatividade quebra a monotonia das aulas e põe os estudantes em contato direto com a representação. (STANISLAVSKI, 1997 [1963], p. 111, negrito nosso)

Os jogos teatrais são uma teia, inscrevem a influência de vários artistas da cena em suas elaborações, como a de Brecht, também descrita nos trabalhos de Koudela, assim como na tradição dos jogos da cultura de vários povos. Em Spolin e Stanislavski o ensino de teatro parte da vivência direta do processo teatral, diretamente relacionado às improvisações, ao invés de iniciar com alguma teorização conceitual que, depois de entendida, será experienciada. O que não significa que o jogador não reflita sobre a ação realizada durante todo o processo, e esta é sua fundamentação, é a união entre teoria e prática, uma retroalimentando a outra, o que também está presente na proposta de conhecimento apresentada por John Dewey.

Sandra Chacra (1961-2004), em seu mestrado em Artes pela Universidade de São Paulo (USP), afirmava o que estamos descrevendo: "Uma explicação dada ao aluno, ao nível puramente teórico, é insatisfatória, porém quando aliada a uma vivência prática, através da dramatização improvisada, seu resultado será mais eficaz." (CHACRA, 1983, p. 37). O jogador aprende o teatro e a vida na relação com o outro em cena e na relação com a própria cena, vida representada em ato, então, é a partir da experiência de jogar, conduzida por um adulto mais experiente nas técnicas teatrais que o aprendizado vai sendo construído e o jogador/ ator vai sendo formado e, enquanto se produzem atos teatrais, teoria e prática estarão unidas, já que não é possível a dissociação de ambas no processo de experiência. Os jogos teatrais propostos por Spolin, como se sabe, são formulados inicialmente a partir do acordo de grupo para a definição de regras; de problemas cênicos de atuação (desafios) apresentados aos jogadores no formato de jogos.

Spolin propõe a organização dos jogos improvisacionais no formato palco/plateia, para que todos os jogadores vivenciem as duas posições: ora são plateia (observadores, analistas, aprendizes pelo observar o que está sendo feito e 
como é feito, um melhor entendimento das propostas pretendidas pelos jogadores e de sua tentativa de realização); ora são jogadores em cena (atuantes, pensadores em ação). Esta forma de organização dialógica contribui tanto para a construção do conhecimento da linguagem teatral referentes ao palco em suas múltiplas variáveis, em ato, como para a formação de plateia para o teatro, pois o educando/jogador vivencia o ser ator e o ser plateia, ambos (plateia e palco) com função definida no momento do jogo. Entretanto, os jogos teatrais podem mais, podem auxiliar o aprendizado da vida, do experimentar das diferentes emoções, do jogar, do agir coletivo, do trabalho coletivo, do perceber o outro, de ver o mundo sobre os olhos do outro, do viver o presente.

Os jogos teatrais, que estiveram em sua gênese, no processo de assentamento de imigrantes, apresenta uma forma intensa e diversificada de ensaio da vida. A descoberta dos "neurônios-espelho" ao final do século XX, é uma das formas que possibilitam e ampliam esta forma de conhecimento (Di Pellegrino et al. 1992, Gallese et al. 1996, Rizzolatti et al. 1996a) e aponta novos caminhos para o sistema dos jogos teatrais. Os neurônios-espelho apontam o cérebro como "simulador de ação", pois ensaiamos ou imitamos mentalmente toda ação que observamos. Essa capacidade se deve aos "neurônios-espelho", distribuídos por partes essenciais do cérebro (o córtex pré-motor e os centros para linguagem, empatia e dor). Não apenas quando executamos uma ação, mas também quando a observamos, neurônios disparam realizando processo semelhante (daí o nome "espelho"). Por isso, essas células cerebrais, esta operação cerebral, apresenta que o observar é essencial no aprendizado de atitudes e ações, como conversar, caminhar ou dançar. Agimos pensando. Os neurônios-espelho permitem que as pessoas executem atividades sem necessariamente pensar nelas, apenas acessando o seu banco de memória, onde, como observa Giacomo Rizzolatti, professor da Universidade de Parma na Itália:

Este procedimento nos permite compartilhar uma esfera comum de ação com os outros, dentro do qual cada ato motor ou cadeia de atos motores, sejam eles nossos ou dos demais, são imediatamente detectados e intencionalmente compreendidos 
antes e independentemente de qualquer mentalização. (RIZZOLATTI; SINIGAGLIA, 2008, p.12)

O que indica que há uma conexão no sistema nervoso entre percepção e ação, e que a percepção seria uma simulação interna da ação. Os neurônios espelhos abrem uma possibilidade extrema de utilização dos jogos teatrais no ensino do lidar dar emoções, no atuar coletivamente, o que abre uma enorme possibilidade com a primeira infância, assim como em parcelas da população que precisa ensaiar o viver emocional, assim como seu expressar, como com autistas ou em determinadas situações de vivencia psicológica ou social.

Neste formato palco/plateia considera-se também os principais procedimentos dos jogos teatrais sistematizados por Spolin, com as regras que estarão sempre a mostra: Foco, Instrução durante o jogo e Avaliação. Aprendese assim o fazer e o experimentar do outro, pensar o jogo jogado, o fazer e o observar, experiências passivas e ativas, o concentrar, o observar ao outro em ação, o perceber consciente da vida sendo vivida. Além disso, Spolin propõe o trabalho com a estrutura dramática a partir do quem (personagem/relacionamento), que pode ser até um objeto; do onde (cenário/ambiente), um determinado local e do quê (ação), o que estaremos a fazer, que podem ser situações do real, daquilo que vivenciamos, situações de outra lógica, da lógica do inesperado.

Deste modo, é possível concretizar uma proposta de ensino e prática de teatro improvisacional que abarque alguns dos principais elementos da arte teatral, direcionando-os a estimular o educando/jogador a vivenciar e a refletir sobre ela, preparando o jogador, mais que para o teatro, para o jogo da vida.

O jogo improvisacional, nesta perspectiva, abre possibilidades de construção de experiências significativas da experiência humana, como algo que se constrói e interfere de modo significativo na vida, algo que altera o nosso modo de vida profundamente, como fruto de nossa existência. $O$ jogo improvisacional, na perspectiva de Viola Spolin, está ligado ao imediato, ao estar em vida, a algo que supere o conteúdo racional da existência, nem apenas a sensação nem a representação. O jogo teatral é uma construção constante do afeto, do conceito e 
do agir coletivamente, o que nos prepara para a vivência dos muitos mundos que se apresentam. Vamos jogar o jogo na vida.

Recebido em 10/03/2019

Aceito em 20/05/2019

\section{Referências}

ALEXANDER, T.M. John Dewey's Theory of Art, Experience \& Nature. The Horizons of Feeling. Albany: State University of New York Press, 1987.

BAND, Ester. Wilhelm Diltheys: Gesammelte Schriften. Verlag Von B. G. Teubener: Berlin, 1922.

CHACRA, Sandra. Natureza e Sentido da Improvisação Teatral. São Paulo: Perspectiva, 1983.

DEWEY, John. Experiência e Educação. 15a edição. Tradução de Anísio Teixeira. São Paulo: Companhia Editora Nacional, [1938] 1971.

DEWEY, John. Experience and Nature. The Later Works of John Dewey, Volume 1, 1925 - 1953: 1925, Ex (Collected Works of John Dewey). Southern Illinois University Press; 1st edition, 2008.

DI PELLEGRINO G, FADIGA L, FOGASSI L., GALLESE V, RIZZOLATTI G. Understanding motor events: a neurophysiological study. Exp. Brain Res. 91:176-80, 1992.

GALLESE V, FADIGA L, FOGASSI L, RIZZOLATTI G. Action recognition in the premotor cor- tex. Brain 119:593-609, 1996.

GADAMER, Hans-Georg. Verdade e Método I. Petrópolis- RJ: Vozes, [1960] 2012. GADAMER, H. Hermenêutica em perspectiva. Petrópolis- RJ: Vozes, vol. I, 2007. GIACOIA JÚNIOR, O. Nietzsche como Psicólogo. São Leopoldo: UNISINOS, 2001. JAMES, William. Principles. The principles of psychology 3 vols. Cambridge: Harvard University Press, vol. 2, pp. 292-299, 1890.

KOUDELA, Ingrid Dormien. Brecht: Um Jogo de Aprendizagem. Ed. Perspectiva, 1991.

NIETZSCHE, F. W. Assim falava Zaratustra. São Paulo: Hemus, 1979.

RAMALDES, Karine; CAMARGO, Robson Corrêa de. Os Jogos teatrais de Viola Spolin: Uma Pedagogia da Experiência. Goiânia: Kelps, 2017.

RIZZOLATTI, Giacomo; SINIGAGLIA, Corrado Las Neuronas Espejo: Los Mecanismos De La Empatia Emocional. Barcelona: Paidos, 2008.

RIZZOLATTI, G.; FADIGA, L.; FOGASSI, L.; GALLESE, V. Premotor cortex and the recognition of motor actions. Cogn. Brain Res. 3:131-141,1996.

SPOLIN, Viola. Improvisação para o Teatro. 5a edição. Tradução: Ingrid Dormien Koudela e Eduardo José de Almeida Amos. São Paulo: Ed. Perspectiva, [1963] 2005.

STANISLAVSKI, Constantin. Manual do Ator. Tradução: Elizabeth Reynolds Hapgood. São Paulo: Martins Fontes, 1997. 
VIESENTEINER, Jorge Luiz. O conceito de vivência (Erlebnis) em Nietzsche: gênese, significado e recepção. Kriterion [online]: Revista de Filosofia. vol.54, n.127, pp.141-155. ISSN 0100-512X, 2013. Acesso em $10 \mathrm{de}$ fev. de 2020. Disponível em: http://www.scielo.br/scielo.php?pid=S0100-

WARDE, M. J. Notas sobre as fontes de formação de John Dewey com base no próprio autor. Brasil, n. 48, p. 169-186, abr./jun. Editora UFPR 171, 2013. 